\title{
Research on the Shot Put Technique of College Athletes based on Network Multimedia Teaching
}

\author{
LIU Zhanfeng \\ Physical Education Department, Xi'an Physical Education University, Xi'an \\ 710068, Shaanxi, China \\ bllw888@163.com
}

\begin{abstract}
With the development of network information, colleges actively carry out the reform of teaching methods in order to meet the requirements of modern education, and the most common measure is the application of multimedia teaching methods. This article attempts to analyze the effectiveness of physical education by suing the network multimedia technology. The author takes shot put course as an example, study on the integrity and continuity of action technology; it requires the various stages of cohesion and coherence, with a reasonable accelerated rhythm. Meanwhile, author analyzes the effectiveness of multimedia teaching in shot put course through comparative test, the result shows that multimedia teaching can improve students' interest in learning, and also will improve the teaching effect; most students get a great progress of shot scores after the experiment and overall results increased by $11 \%$. On this basis, we put forward some suggestions on curriculum innovation in shot put teaching
\end{abstract}

Keywords: Network multimedia, shot put, teaching method, information transmission, sports education

\section{Introduction}

At present, in order to adapt to the information and the digital tide of the society, the educational circles in China can realize the modernization of teaching, and actively carry out the reform of teaching methods and methods. This innovation in practice the most common performance, more in the course of teaching in the use of multimedia teaching means. Under the influence of this trend, the sports industry will be applied in the course of the teaching of physical education by means of media presentation and courseware making of some other subjects. But at present domestic sports most workers using multimedia teaching, media use mostly slides, video and projection, the instruments of human can be poor editing [1]. Real multimedia teaching demonstration function to the fullest of computer technology used is not too much, even uses the computer to carry on the teaching, also is some simple visual media information finishing editing, courseware making, whether it is from the form, the information transfer direction and amount of information are still relatively limited, which for us to improve our teaching methods and improve the teaching effect of the final objective function is not obvious. But also does not reflect the true meaning of quality education in the education reform of our country, not to play the main role of students in the learning process. And in the past, the information media is different, the computer is not a passive acceptance of the information provided by others, but can actively search for the information needed, which is what we usually say human computer interaction. This interaction is not only reflected in the use of a single machine, more important is reflected in the computer and the communication between the computers[2]. Because only through the computer network, in order to achieve the greatest degree of information sharing and real-time access to resources; as long as there is a computer and a network interface, we can in any time, any 
place very quickly get their required information. If we can combine these functions into our practical teaching, it is of great significance to play the main role of the students in the teaching process.

This paper attempts to in the education circle to promote modern education technology trend, in the syllabus of physical education reform, sports department technology class number is decreasing trend of a kind of multimedia and network technology as the means of supporting a new practical teaching method. The main purpose of the author is trying to use the rich amount of information of the Internet and multimedia technology, interactive, access to information real-time, convenience and other advantages, the application of network multimedia technology in the sports teaching process, in order to achieve on the basis of the existing class, the maximum guarantee and improve the teaching quality[3]. Enable us in teaching breakthrough the limitation of school and classroom, the regular teaching time, so that students can be flexible to master their learning time and environment, in order to achieve us in teaching implement the idea of quality education in the national education reform, give full play to students' initiative, make sports departments in the implementation of training students' ability, combined with modern educational technology, in the teaching reform of the road has new breakthrough and progress, and for the future to instruction in the teaching of physical education and modern educational technology in combination of research workers to provide some reference. The theoretical basis of the application of modern educational technology is the constructivism learning theory, which emphasizes the main body position of the students in the learning process. Previous most sports workers in shot put teaching hours, in teaching the students' action is in accordance with the textbook technical norms movement essentials, very strict according to the textbook requirements step by step teaching. In order to improve the teaching effect, in this regard for reform is the most significant example is the whole teaching procedure to replace the traditional teaching program ", because" the whole teaching procedure conforms to throw teaching from easy to difficult, step by step teaching principles and action skills formation rules, shorten the hours of teaching, emphasizing the technical aspects of coherence, accelerated the shot put a complete technical mastery, reduce or avoid the disconnection of the technology for a long time in the teaching of unresolved, and received good results.

\section{Literature Review}

\subsection{Application of Multimedia Technology in Sports Course}

The application of multimedia technology in the teaching process has a positive influence to sports course. First of all, an in-depth research and analysis of the teaching material, according to the content of teaching materials of the characteristics and to determine the level of knowledge and learning, in every stage of teaching choose different optimal media, with the objective of achieving the best teaching effect[4]. This method gives prominence to the teaching input and feedback, and expands the teaching information transmission, enrich the learning activities of students situation, make teaching activities become the process of students' autonomous learning is a kind of ideal of modern sports teaching methods. Multimedia technology has many advantages as follows:

1) Imagery training: imagery training is in sports teaching and training process with more than a mental skill training method, it is refers to in the suggestive language under the guidance, in the mind repeatedly imagining the scene of some movement or motion, this method can improve the motor skills and ability of emotional control. The imagery training power to establish and consolidate the correct action to finalize the design, help to speed up the movement of skilled and enhance memory. The combination of media technology with the idea of 
psychology training, so that the combination of the characteristics of the two complements each other. In the course of teaching, the teacher adjusts the teaching process according to the actual situation of the students. Students in learning technical movement in the process, watching a recording of high level athletes technology, in the students to establish a correct concept of skill and movement, imagery training; at the same time, through live video of Microteaching technology, students can see self-technology action video imagery training and action practice, through the comparative analysis, finding out errors or gaps their movements and to take the corresponding method from me to solve, and eventually reached to improve teaching effect.

2) Stimulate student's interest: interest is the students learning of the original power, is a person seeking knowledge, grasp certain things, involved in an activity and psychological tendency of positive emotions, is to encourage students to study in very realistic, the most active factors. In sports practice, especially in the track and field of some teaching content, because the technology is monotonous, boring, it is difficult to arouse students' interest in learning[5]. This method is to change the malpractice of the practice teaching of PE teachers in sports teaching before or the beginning of sections after school, students, watch some wonderful video game, through intense live video game, and stimulate the students' learning interest. At the same time, let the students have an intuitive notion of the content, and produce the desire to active learning, the teachers and students in the future of the teaching process, students can positively and actively to accept the teacher to teach content, such change from passive learning to active learning, and make the teaching effect is greatly improved.

3) Multimedia CAI: traditional teaching media refers to the textbook, chalk, blackboard and the teacher's explanation and demonstration based, when the introduction of Multimedia CAI technology, teachers can according to the need of teaching, the realization of human-computer dialogue, free calls and launched a variety of teaching activities[6]. For example, when encountered some of the students in the teaching process of difficult to understand and grasp the key and difficult problems, teachers can according to the problem, the collection and special editor of the shape, sound and image data, this method to help the students understand the problem, to establish a correct concept of action; teachers can also put some teaching software are introduced to the students, let the students in the class have to study or review. In this way, students receive information to broaden the way, but also in the form of more active, so that the teaching effect has been a qualitative leap.

4) Improve teaching efficiency: in most of the institutions of higher learning, because it has not established the professional sports, only public physical education, so the school's requirements for PE teachers is versatile teachers; and in reality, it is difficult to have which a physical education teachers can do for each sport can make a perfect demonstration. Especially when teacher's age reach a certain limit, it is more difficult to achieve this point. When we apply the multimedia teaching demonstration, in each of a teaching project, using this technology will be the project of some key and difficult, and they often encounter in the course of previous problems into CAI courseware. For example, in the middle of a continuous action an action link, in the teaching is teachers demonstration and some of the media to highlight the performance; at this time, we can use the number of multimedia making software will come out of this part of the production performance, so as to ensure correctness and completeness of the students to accept information, so as to make the whole teaching process complete and smooth. 


\subsection{Shot Technology Teaching}

The teaching of shot putting technique, for example, the traditional teaching mode analysis, the previous sports workers in shot put teaching, the methods and steps is generally carried out in accordance with the old track and field textbook required, that is, we often say traditional teaching method. To sum up mainly is shot put technology is divided into holding method, pre swing, sliding, finally forced and maintain body balance, several technical aspects, according to the primary and secondary position of each technical link in the full technology was successively decomposition of teaching. Traditional teaching method using reversible teaching method, just beginning to learn the shot is the most difficult to master final push technology, which is contrary to the from easy to difficult, step by step teaching principles[7]. Through the practice proof, standing shot put and gliding shot put final exertion of force mechanism is not exactly the same, is coaxed and real inside and outside because conditions are different. To practice the shot technique is not conducive to the students to master the complete technical slip shot put as soon as possible with a long time. Decomposition exercise time longer, more times, students in mind to establish a single technology of sensory motor will be stronger, built in the brain of stereotypes is strong, thus ignoring the relationship between the technologies. Due to the traditional teaching method "complete technical practice time is relatively short, not only the coherence links poor, nervous movements, uncoordinated and the technical link between appear not to cooperate closely, so that has mastered the single technique with complete technical training speed and deformation, and the emergence of excess error action, or even complete technology have been destroyed. Through the above analysis, we understand that the "traditional teaching method" of the two main drawbacks. In order to solve these two problems, our country's sports workers from the technical teaching of various related angle, carried on the effective reform.

In recent years, some sports workers through relevant theories of learning and master the latest technological developments and some of the latest theoretical research, timely teaching technology and the latest technology in combination with the theory, and achieved good results[8]. For example: in recent years, China's sports scientific research staff, coaches in the horizontal movement in China is developing very quickly the women's shot put project training process, and gradually formed a own style as China shot put technology, the technology focus on technical movements of the integrity and continuity, pay attention to "sliding rotation speed emphasizing the final exertion prominent forward, requirements of each stage of cohesion and coherence, accelerated pace of reasonable, pursuit" in the whole process of shot put, constantly appliance speeded up until the would last with the fastest speed on shot launched the overall effect ". According to the thought of technology reformation in the forefront of China's sports teaching physical education workers in the actual teaching work also corresponding changed some techniques for teaching requirements, teaching requirements and teaching methods, create a set of excellent teaching. Another simple gliding shot putting technique of teaching is in the traditional back to the sliding push shot put technique, and saves the pendulum swing leg of the pre stag". According to the research results of China's scientific research personnel: the original in order to achieve reflection start effect and the use of pre swing - mission knees technology, lack of strength of lower limbs for beginners have serious obstacles, simple gliding shot put technique can solve this problem by using the method of Physical Education teachers, through the contrast experiments show that has good feasibility[9]. Analysis shows that simple sliding push shot put technique from a technical point of view in full compliance with human anatomy, physiology, sociology, psychology and biomechanics principle, strengthen the coherence of a series of actions, therefore received the good effect. Another some of the reforms in the teaching process of physical education teachers is according to the characteristics of modern back gliding shot putting technique is mainly manifested in the fast, in order to seek more in line with the 
push of methods of teaching shot techniques, to link up with the technology as the focus, to improve the speed shots as the center, to train and to improve the ability of the students for the purpose. So take the programs from easy to difficult, sliding distance from short to long, weights from light to heavy, movement speed from slow to fast. The intensity of the action in the ascending and. This experiment adopted the outline forming to improve the technical details to improve the teaching program of complete technology, more conducive to the students to master modern push shot put technique, form a good rhythm, establish the correct dynamic stereotype, for the cultivation of students and improve, significantly better than the conventional teaching methods.

\section{Research Design}

\subsection{Experimental Objects}

Through the analysis in the sports teaching practice from the multimedia technology in the above, we can see, multimedia technology impact on our physical education industry, from the teaching ideas and teaching methods, from the teacher in class to the students' learning, under its influence occurred huge change. The use of multi-media teaching, due to the amount of information transmitted, and the picture changes quickly, so it can make the students of the brain in the positive working state, can accelerate and strengthen the brain about the logic of the in the brain the storage area left profound action representation, to raise students' interest in learning, and fully mobilize students learning enthusiasm has played a good role. This teaching experiment chooses students from Xi'an Physical Education University as the research object. The test experiment was carried out respectively before the basic body shape index, the two classes of students' special physical quality and special performance.

Table 1. Basic Body Shape Indicators of Two Groups of Students

\begin{tabular}{|c|c|c|c|c|}
\hline \multirow{2}{*}{ Group } & \multicolumn{2}{|c|}{ Height $(\mathrm{m})$} & \multicolumn{2}{c|}{ Body weight $(\mathrm{kg})$} \\
\cline { 2 - 5 } & $\overline{\mathrm{X}}$ & $\mathrm{S}$ & $\overline{\mathrm{X}}$ & $\mathrm{S}$ \\
\hline control group & 1.75 & 0.03 & 65.10 & 3.54 \\
\hline experience group & 1.76 & 0.03 & 63.53 & 4.25 \\
\hline T value & \multicolumn{2}{|c|}{0.952} & \multicolumn{2}{c|}{1.244} \\
\hline P value & \multicolumn{2}{|c|}{$<0.05$} & \multicolumn{2}{c|}{$<0.05$} \\
\hline
\end{tabular}

Table 2. Special Physical Quality Indexes of the Two Groups

\begin{tabular}{|c|c|c|c|c|c|c|}
\hline \multirow{2}{*}{ Group } & \multicolumn{2}{|c|}{$30 \mathrm{~m}$ standing start } & \multicolumn{2}{c|}{ Standing long jump } & \multicolumn{2}{c|}{ shot put } \\
\cline { 2 - 7 } & $\overline{\mathrm{X}}$ & $\mathrm{S}$ & $\overline{\mathrm{X}}$ & $\mathrm{S}$ & $\overline{\mathrm{X}}$ & $\mathrm{S}$ \\
\hline control group & 4.10 & 0.22 & 2.82 & 0.12 & 8.12 & 0.71 \\
\hline experience group & 4.00 & 0.19 & 2.85 & 0.12 & 7.55 & 0.71 \\
\hline T value & \multicolumn{2}{|c|}{1.823} & \multicolumn{2}{c|}{1.008} & 2.512 \\
\hline P value & \multicolumn{2}{|c|}{$<0.05$} & \multicolumn{2}{c|}{$<0.05$} & $<0.01$ \\
\hline
\end{tabular}

The statistical results show that the two classes of students the basic body shape without significant difference; special physical quality, 30m station vertical starting and standing long jump, there was no significant difference between the two groups, but throw in situ shot and slide push shot had highly significant difference. This show that the power quality of two classes of students has the obvious difference, so that the shot result after complete technology still has obvious difference. 


\subsection{Research Method}

1) Literature method: through various channels, reference room of the library reading room of the University and other colleges and universities library reading room, the Institute of physical education in the library, other department, Institute of physical education, access to at home and abroad about education theory, multimedia teaching theory, learning theory, educational psychology, learning psychology, technical analysis, to explore new technology, instructional technology, technology reform of teaching methods of literature data, grasp today the new education teaching idea and recent technology trends, to provide a theoretical basis for the teaching experiment.

2) Network retrieval method: on the website of CNKI, domestic famous universities, major domestic sports colleges and universities website read widely about the sports teaching, audio-visual teaching, multimedia teaching, teaching technology, technical reform, new teaching methods, computer aided teaching aspects of theoretical journal articles and documents. Learn from their design ideas, to draw on their strengths, to sum up their deficiencies, so that they have a comparative understanding of domestic and foreign situation at home and abroad.

3) Survey method: before the teaching experiment, I to the audio-visual Department of South China Normal University experts teacher ask about remote teaching theories and pay attention to the problem, understand the development of the distance education at home and abroad. In the holidays, through a variety of relationships to other sports colleges and universities students to understand the development of long-distance teaching of sports. Before the teaching experiment, through the method of questionnaire, oral interview to understand sports college students' Internet use, facilities, the computer knowledge, and use as divided into control and experimental classes, the placement basis.

4) Mathematical statistics method: before the experiment teaching students the basic body shape index, special physical quality, special achievements and data are in the objective test obtained and the test data by SPSS statistical software $t$ test, single factor variance analysis; the survey results by using attitude measurement tables are analyzed, according to the results of the analysis, to prove, discussion teaching effect, and students of multimedia teaching attitude.

\section{Empirical Analysis}

\subsection{Design of Teaching Process}

The teaching process is the bilateral activities of teachers and students receiving information, all of the components of the teaching process, internal and external conditions are interrelated. In this experiment, we try to modern teaching theory and teaching design theory as a guide, the use of the advantages of multimedia network, teachers, students, media, and other elements achieve a rational, systematic and orderly mutual relations, optimize sports teaching, forming a stable structure of teaching process. In this teaching experiment, we are basically the same as the design of the teaching schedule in the control class and the experimental class, but the teaching methods of each class are very different. 
- 1 class hours: test students' basic body shape index, special physical quality, special achievements, as experimental teaching placement basis and evaluation of the teaching experiment of the original data.

- 2class hours: shot technology induced by teaching, so that students understand the physical exertion sequence right shot-putting exertion.

- 3 class hours: shot holding method, to enable students to understand and master the basic technique of in situ lateral shot put.

- 4-7class hours: back gliding shot put technique, interspersed with special physical exercises.

- 8 class hours: mid-term technical assessment standards, as part of the original data of this teaching experiment, and to examine the previous stage of teaching.

- 9-15 class hours: review, consolidate and increase the back sliding shot-putting technique, strengthen the each part of the action, technical details, interspersed with special physical fitness exercises.

- 16 class hours: the overall technical level test.

Because only the importance of knowledge imparting is widespread in the teaching field, do not attach importance to the cultivation of ability and the comprehensive quality of; the influence of Teacher centered theory, neglecting students' subjective role play; the influence of behaviorism, ignore the cognitive information processing and significance and guidance for students. According to the above problems, we are in the process of designing the teaching experiment, and always adhere to the students as the main body, teachers as the guiding ideology of teaching. In the classroom structure a relaxed and happy atmosphere, so that students in class always have a sense of ownership of state of mind, know that they are learning in the main factors, so as to be able to actively take the initiative to learn and master the knowledge. After each teaching unit, the teacher asks the students to use their own language to express them, so that the perceptual knowledge rises to the rational cognition. In addition, in the teaching stressed that allow students to study the form of group practice, let the students mutual evaluation; or when practicing in a practice, teachers and students together to watch, after practitioners complete the movement, let practitioner's classmates comments, and then by the teacher carries on the review and summary, through these ways to improve the teaching quality of the students. Normal outdoor technology class time, when we will be applying this teaching form to practice specific approach is: in teachers can try to shorten the explanation and demonstration of the time, reflected "practice" principle, the class more time for students to practice; and before each teaching unit, to tell the teachers and students of the prefabricated on this part of the contents of the network courseware the URL, and then let the students through their own online learning, first from the network obtained this unit and the basic content of the concept, form a certain representation in the mind. In formal technical class, the teacher let the students give their advance through the learning and understanding of the action, using their own language speak for everyone to hear, then teachers and students expressed action the correct concept of place for sure, not appropriate place into correct, in order to strengthen the students' correct understanding of action, and then through the demonstration of the teacher himself, explain, let the students practice.

In this process always adhere to the students as the main body, teachers just to guide and a supporting role let the students through their own knowledge and personal experience as main means to learn and master the knowledge, to this kind of teaching way strive to achieve the best teaching effect. About in the formal class time outside of school hours, teachers in the form of homework for students to surf the Internet to learn the teaching content, in order to let the students to review the old content and preview new 
knowledge. For teachers, teachers in advance by means of some media editing software will be some of the media data edit combination, to page placed on the network and on the web page design some interactive operation interface and menu operation interface, by the students according to their own situation, choose the content. Teachers can also place the subject of a number of operations on a web page, such as some wrong motion graphics and provide electronic bulletin board for students to express their views, teachers get to the Internet to collect information again: their views; or when teachers and students are online, you can chat room or some other chat tools to discuss problems together. In this way, teachers and students to teach the way to receive information will be more direct, more intuitive and lively form. If a student has a problem, it can be immediately to the teacher to ask questions and get answers; teachers can also be directly to the students through this form of questions, such as the students found what the problem of immediate correction.

\subsection{Students Shot Standards}

In the primary stage of motor skill learning, for the experimental class teaching form we mainly use of the network multimedia courseware text to explain, image and model demonstration function, with classroom practice to make students acquire knowledge actively. In class exercises we take collective exercises. Although individual students physical qualities, the ability to accept a certain gap, but according to a survey before the experiment, most of them did not learn the sliding shot putting technique, the level of technology is almost the same. In the teaching, give full play to the leading role of teachers to guide students through the network assisted learning courseware, the key technology of a clear understanding of the last exertion force order, each link of accelerated rhythm. Emphasize the imitation, experience and practice, find the muscle feeling. This practice can increase exercise density, arouse students' enthusiasm in practice; promote the students to enter the stage of differentiation.

Table 3. Demonstrating Compliance of Shot Put

\begin{tabular}{|c|c|c|}
\hline content & experience group & control group \\
\hline Highest standards & $11.74 \mathrm{~m}$ & $11.88 \mathrm{~m}$ \\
\hline Minimum standards & $8.23 \mathrm{~m}$ & $9.30 \mathrm{~m}$ \\
\hline Excellent rate & $28 \%$ & $40 \%$ \\
\hline pass rate & $95 \%$ & $100 \%$ \\
\hline Non-pass rate & $5 \%$ & $0 \%$ \\
\hline
\end{tabular}

Table 4. Technical Evaluation of Shot Put

\begin{tabular}{|c|c|c|}
\hline content & experience group & control group \\
\hline Excellent $(9)$ & 2 & 1 \\
\hline Good $(8.0-8.9)$ & 13 & 15 \\
\hline Medium $(7.0-7.9)$ & 3 & 2 \\
\hline Pass $(6.0-6.9)$ & 0 & 1 \\
\hline Fail $(<6.0)$ & 0 & 1 \\
\hline
\end{tabular}

Experimental teaching as an attempt to reform the teaching method by the time to improve the quality of teaching, analysis and evaluation of the best method is summed up from the teaching results in the teaching experiment of this time is no exception. Two aspects of the remote network aided teaching experiment from the subjective and objective results of evaluation. On learning attitude, cognition, skill evaluation scores and standard scores quantified scientifically, and make scientific analysis of the results. 
Evaluation of the results of learning is an important part in teaching design. It can provide teaching information feedback, to promote students' learning, can help teachers to find out the knotty problems in teaching and improve the teaching plan, to sum up the laws of teaching, so as to continuously improve the teaching. In this teaching experiment, we mainly study the objective result evaluation, and study the subjective result evaluation as a supplement, so as to evaluate the whole learning process. The basic skills of the students and the basic ability of the test, the main means of technical assessment through the method, after 16 hours of teaching experiments in accordance with the conventional technical standards for assessment standards.

\subsection{Comparison of Two Groups of Students}

In any form of multimedia teaching, the choice of teaching media are not blind and random of, it is to the system scientific method as a guide, around the ultimate goal of teaching, in order to solve the teaching needs to optimize the teaching effect and teaching strategies. Therefore, the choice of the media is not only conducive to the completion of teaching purposes, but also conducive to the solution of the focus and difficulty in teaching. Therefore, in experiment teaching, we according to the characteristics of back gliding shot putting technique, according to the knowledge of every class and should reach the teaching aim to determine the design and use of media, to choose the appropriate sports technique teaching in such a way as to physical exercise and motor skills to master teaching. We according to the following characteristics of constructivism teaching mode: emphasize the interaction between teachers and students; teachers should play a leading role as study guides.

Table 5. Achievement Comparison of Sliding Shot Putting

\begin{tabular}{|c|c|c|}
\hline \multirow{2}{*}{ Group } & \multicolumn{2}{|c|}{ Sliding shot putting (m) } \\
\cline { 2 - 3 } & $\overline{\mathrm{X}}$ & $\mathrm{S}$ \\
\hline control group & 10.75 & 0.67 \\
\hline experience group & 10.32 & 0.93 \\
\hline $\mathrm{T}$ & \multicolumn{2}{|c}{1.633} \\
\hline P value & \multicolumn{2}{|c|}{} \\
\hline F value & \multicolumn{2}{|c|}{2.665} \\
\hline
\end{tabular}

Table 6. Technology Evaluation of Sliding Shot Putting

\begin{tabular}{|c|r|c|}
\hline \multirow{2}{*}{ Group } & $\overline{3}$ Technology evaluation \\
\cline { 2 - 3 } & \multicolumn{3}{|c|}{$\mathrm{S}$} \\
\hline control group & 7.9 & 1.9 \\
\hline experience group & 8.5 & 0.4 \\
\hline $\mathrm{t}$ & \multicolumn{2}{|c|}{1.228} \\
\hline P value & \multicolumn{2}{|c|}{$>0.05$} \\
\hline F value & \multicolumn{3}{|c|}{1.507} \\
\hline
\end{tabular}

Before the teaching experiment, we have the two class's in situ push shot scores and gliding shot put performance of pre-acquisition. Two classes of students in situ and slide push shot, there was significant difference, the experimental class performance and the control class achievements have great differences. After a period of teaching, in the different teaching methods of single factor, two classes of students has great progress, but the method of experimental teaching in the experimental class performed increased more significantly, from there to the highly significant difference, there was no significant 
difference between the two groups. It is proved that the network aided teaching methods have received a good teaching effect.

\section{Table 7. Teaching Effect After Experiment}

\begin{tabular}{|c|c|c|}
\hline content & experience group & control group \\
\hline Average score before experiment & $7.30 \mathrm{~m}$ & $8.00 \mathrm{~m}$ \\
\hline Average score after experiment & $8.07 \mathrm{~m}$ & $8.43 \mathrm{~m}$ \\
\hline Achievement ratio & $11 \%$ & $5 \%$ \\
\hline
\end{tabular}

After a comparison of the two classes we found new teaching methods have significant results, in order to further demonstrate, we the two classes were vertical comparison, through before the experiment and after the experiment that its comparisons, to further discuss the teaching experiment of the effect. We before doing the experiment, two classes of complete technology (back gliding shot put) original results to do a detailed record, after the shot teaching of different teaching methods, both of the two classes has improved significantly. Progress of class to us, two classes of students before the experiment and experimental achievement respectively before and after paired t test, students before and after the experiment achievement has significant difference, $\mathrm{P}<0.001$, thus we can concluded that although the two classes of students in after a stage of shot put teaching has great progress, but the effect is more significant, and in the whole process of teaching, two classes of students teaching activities by my organization and implement, in addition to teaching methods, teaching experience and ability, etc.. subjective factors can be ignored, so that the experimental class students accept the teaching methods, namely, network assisted teaching method is more effective.

\section{Conclusions}

Through the above on the multimedia technology conditions, shot practice teaching reform of the course of the examples, we can see the following characteristics and reform of the teaching of shot putting technique and the new development of theory and technology closely integrated. In recent years, all the teaching of shot putting technique reform pay attention to improve students' movement speed and hand speed, so as to ultimately improve the performance of shot put. Because in the medium or in Institutions of higher learning, the teaching of shot putting technique of object is ordinary students, and not the senior players, so some difficult technical details does not require students to master the, the student is also very difficult to master. And in order to improve the economy and effectiveness of the action technology play the overall effectiveness of the technology, the teaching of shot putting technique developed toward the direction of simple and practical. According to the characteristics of students is to study the main body of the flexible arrangement of teaching, break the rules of traditional teaching methods, flexible arrangements for teaching. In the teaching, is no longer a one size fits all, from the teaching process to teaching is carried out according to the textbook; but according to the characteristics of the students and problems appeared in the process of teaching, specific issues specific analysis, adopt new teaching methods, design new teaching program to ultimately improve the quality of teaching. Shot put technique teaching reform rely on biomechanics, education, psychology and other disciplines theory, so that the shot put technique teaching reform towards a more systematic and scientific direction.

To the experiment teaching in the current multimedia distance teaching, and due to the reform of PE teaching syllabus, sports department technology lesson number showed a decreasing trend and research a kind of takes the network and multimedia technology as auxiliary means, a new practice teaching method. The author tries to use the rich amount of information of the Internet and multimedia technology, interactive, access to real-time 
information, convenient, don't you think the advantages of access to information in time and place restrictions, enable us to break the limitations of the school and classroom, the regular teaching time in teaching, so that students can master their learning and their learning environment flexible, more important is the use of the students in their spare time, to enable students to both hands and brains of the effect. But we also see, only to rely on discipline theory and the thought of teaching reform to shot practice class teaching, although the shot put teaching a great leap in Teaching Ideological and theoretical guidance, but in the actual operation forms is still relatively boring teachers output student information and accept the information channels for a single, especially for shot put the basic physical projects. It is difficult for students to this technology is of interest and actively take the initiative to learn, this is the shot put teaching effect is difficult to have a large increase in one of the reasons.

\section{References}

[1] M.Alavi, "The Challenges of High School Counselors in Work PlaceOriginal”,Procedia - Social and Behavioral Sciences, vol. 46, (2012), pp.4786-4792.

[2] R. A. Sabella, "School counselors perceived importance of counseling technology competencies", Computers in Human Behavior, vol. 26, (2010), pp. 609-617.

[3] N. R. Mastroleo and R.Turrisi, "Examination of posttraining supervision of peer counselors in a motivational enhancement intervention to reduce drinking in a sample of heavy-drinking college students",Journal of Substance Abuse Treatment, vol. 39, (2010), pp. 289-297.

[4] R.Khansa, "Teachers' Perceptions toward School Counselors in Selected Private Schools in Lebanon”,Procedia - Social and Behavioral Sciences, vol. 185, (2015), pp. 381-387.

[5] Z. Huang and M.Benyoucef, "From e-commerce to social commerce: A close look at design features",Electronic Commerce Research and Applications, vol. 12, no.4, (2013), pp. 246-259.

[6] K. Anand, "Context-general and Context-specific Determinants of Online Satisfaction and Loyalty for Commerce and Content Sites",Journal of Interactive Marketing, vol. 24, no. 3, (2010), pp. 222-238.

[7] S. E. Carrell and M. Hoekstra, "Are school counselors an effective education input?"Economics Letters, vol. 125, (2014), pp.66-69.

[8] L. Michel and R. Mohammad, "The effects of social media based brand communities on brand community markers, value creation practices, brand trust and brand loyalty", Computers in Human Behavior, vol. 28, no. 5, (2012), pp. 1755-1767.

[9] Z. Catts, "Certified Genetic Counselors: A Crucial Clinical Resource in the Management of Patients with Suspected Hereditary Cancer Syndromes",Review ,Surgical Oncology Clinics of North America, vol. 24, (2015), pp. 653-666.

\section{Author}

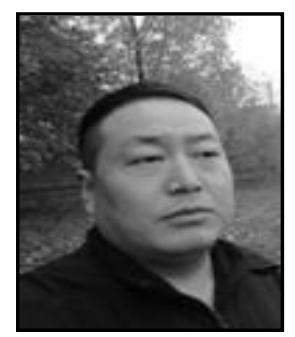

LIU Zhanfeng, 1978,8 Xi'an, Shaanxi ,China .Current position,grades: Physical Education Department, Xi'an physical education institute, Xi'an, Shaanxi, China. Scientific interest: Analysis of Sports Biomechanics and Coordination. Publications: More than 6 papers published. Experience: $\mathrm{He}$ has teaching experience of 13 years,has completed three scientific research projects . 
International Journal of Signal Processing, Image Processing and Pattern Recognition Vol. 9, No. 4 (2016) 